\title{
LECTURERS' AND STUDENTS' REFIECTIONS ON A BILINGUAL PROGRAMME
}

SANDISO NGCOBO

\section{Introduction}

The high failure and drop-out rates among the majority of African students in tertiary institutions in South Africa has, among other reasons, been attributed to the use of English, typically the second language of students, as the main medium of instruction. According to a report by Macfarlane (2007), this notion has been confirmed by students in a study conducted jointly by the Human Sciences Research Council (HSRC) and the Council on Higher Education (CHE) among 3,328 students who dropped out of seven universities between 2000 and 2002. An overwhelming $77 \%$ indicated that difficulty with the language of instruction at their institution was the reason for their withdrawing. These findings could suggest that the introduction of mother tongue instruction (MTI) would be useful and welcomed by both students and various stakeholders in education. Such a move might not prove difficult to implement given that the Language Policy for Higher Education (RSA. Department of Education, 2002) requires the development of African languages as media of instruction. Moreover, many institutional language policies are aimed in this direction.

Nonetheless, various studies on the role of African languages in education and higher domains of society (Dalvit \& De Klerk, 2005; Makhode, 2005; Ngcobo, 2001) have revealed negative and ambivalent attitudes. For instance, Makhode reports that the ministerial committee established to advise on the development of indigenous African languages as media of instruction in higher education found that there is a strong 'preference for English instead of African languages in all the formal sectors of society, both in private and public' (Makhode, 2005:4). This suggests that in South Africa the relationship between African languages and English is diglossic. In this respect, Fishman (1977) defines diglossia as a situation in which two languages are used differently in the community; one in formal settings and the other in informal settings. The challenge is then to find a way to bring it to the society's attention that the issue is not entirely about language and that cognitive, affective and social development skills will contribute to success across a wide spectrum (Webb, 2002, 2004). 
In light of the continued academic issues facing the country and the amount of research pointing to the benefits of MTI, there is a need to deepen a discussion on 'attitude change.' Various national and international studies (Cummins, 2005; Heugh, 2005; Ramani, Joseph \& Modiba, 2007; Shembe, 2003; Webb, 2004) testify to the positive effects of MTI on second-language achievement and educational development. Regarding attitudes, Triandis suggests that one of the ways in which they can be changed is:

[by] first changing the cognitive component (e.g. with new information), the affective component (e.g. by pleasant or unpleasant experiences in the presence of the attitude object) or the behavioural component (e.g. by norm or behavioural changes). (Triandis, 1971:142)

Thus intervention programmes that explore the use of mother tongue as a resource to teach critical skills in higher education seem appropriate at foundation or firstyear level. Such skills would inevitably include academic literacy and communication proficiency since these have been identified as major factors that affect particularly first-year English Second Language (ESL) students' academic performance and thus retention and progression rates (Van Dyk, 2005; Weideman, 2006). It is hypothesised that the role of an African language (isiZulu) in higher education could be favourably viewed if used together with English, and particularly if the experience is considered beneficial in facilitating teaching and learning.

Such an approach addresses a weakness in previous attitudes studies in that they have not been conducted in tandem with a programme that utilises a home language as medium of instruction. This approach has the potential to enable respondents to base their assessment on practical experience rather than emotions alone. Hence, the study provides a better understanding of attitudes towards the role of African languages in education. Moreover, some of the essential partners (ESL lecturers and their students) in the implementation and the acceptance of language education policies and programmes have either been ignored or investigated independently from each other in language attitudes studies.

On the one hand, language lecturers' views are critical due to the fact that their formal and informal language learning experiences can have a powerful impact on their beliefs (Johnson, 1999, cited in Zeng \& Murphy, 2007:1). If, for instance, language lecturers who are ESL speakers developed their English competency in an environment that emphasised native speaker competency and English supremacy, they are unlikely to support the use of students' first language (LI). On the other hand, university students are considered old enough to make decisions and to hold certain views about their education. For this reason their contribution is equally important. The new positive experience with a primary language in education could influence these beliefs in both groups. 


\section{Project setting}

The Mangosuthu University of Technology (MUT) in Umlazi township, south of the city of Durban, South Africa, forms the site of this study. Umlazi township is a residential area historically and dominantly occupied by Africans who are mostly isiZulu speakers. MUT was initially established to cater for the tertiary education needs of African students only. Despite new policies that emphasise integration across all spheres of society, the majority of previously black educational institutions, such as MUT, tend to remain black in terms of student enrolment and language used socially. It is for this reason that the reported study sought to utilise the students' familiar or primary language (the language used most often) (Webb, 2004) to enhance the teaching of academic literacy and communication skills that are often taught only in English. IsiZulu was the only language paired with English due to its dominance on campus (at my estimation, $\pm 90 \%$ ), in the province of KwaZulu-Natal (81\%) and nationally (23.8\%) (Statistics South Africa, 2003).

\section{Participants}

The lecturer sample comprised ten respondents taken from the staff component of eleven lecturers who facilitated the Communication and Academic Literacy Skills module for engineers at foundation level. This was considered a significant sample since it is unusual to have so many language lecturers teaching the same group of students at one university. The student sample comprised three hundred respondents randomly selected from a group of about five hundred students registered in the first semester of 2008 for the Extended Curriculum (Degree) Programme (ECP) in Engineering.

\section{Instrument design}

In order to investigate the goal of the project I had to design and implement two research instruments. First, there was dual-language instruction (DLI) teaching and learning material (also referred to as a bilingual programme or a study guide). Second, there were two questionnaires, one for students and the other for lecturers (see Appendices 1 and 2).

\section{Dual-language instruction material}

The study developed gradually over four semesters in the period 2006 to 2008 and piloted teaching and learning materials that used both English (65\%) and isiZulu (35\%) to present content for a course in communication and academic literacy skills that previously had been presented in English only. The view of literacy that informs this course is that it should not be limited to what happens in classrooms; rather, it should include the social nature of literacy (Helmberger, 2006; Weideman, 2006). This view is preferred because it extends literacy to include the communication skills that ESL learners need to develop in order to be able to operate effectively in a range of formal and informal situations within the multilingual society of South Africa. For these reasons an integrated approach had to be adopted in the organisation of study 
guide material. I agree with Ngwenya that the integrated approach at university level is necessary as an alternative to apartheid education in schools because it (apartheid education):

[t]ended to leave many students' English competency grossly inadequate, through its emphasis on rote-learning such as parsing of words and sentences and memorization of facts for regurgitation in tests and examinations at the expense of understanding and critical thinking. (Ngwenya, 2006:23)

As a result, communication skills in this study were integrated with the academic literacy skills that students require in their content subjects while using isiZulu in order to determine the impact on the overall academic performance of students. Moreover, I wanted to determine whether or not the approach would be perceived favourably by the respondents.

Thus, the study investigates the sociolinguistic dimension of the DLI programme. Lee (2002) aptly maintains that the investigation of language attitudes within a bilingual programme can essentially be ascribed to the fact that on the one hand, various types of bilingual education programmes often make implicit assumptions about the kind of language situation that exists in a given community and about the kind of language situation that ought to exist in that community. On the other hand, the assessment of language attitudes provides an indicator of current community thoughts and beliefs, preferences and desires. The investigation of language attitudes, therefore, gave the participants the opportunity to verbalise their language preferences after participation in the DLI programme. Their responses were then used as an indicator of whether or not the project succeeded in its set objectives.

\section{Questionnaire}

According to Cohen, Manion and Morrison (2001), surveys are useful in gathering data aimed at describing the nature of existing conditions. More specifically, Johnson (1992) and Nunan (1992) assert that survey methods are suited to investigating a wide variety of linguistic issues including language attitudes. Therefore, in an endeavour to investigate the impact of the DLI study guide on biliteracy, bi- or multilingualism and language attitudes, two questionnaires were used - one by lecturers and the other by students.

The questionnaires contained both closed and open-ended questions. Closed-ended questions required respondents to indicate their opinions by locating their response on a rating scale, as in the Likert-type multiple-items scale (Likert, 1932). The scores for the items ranged from a minimum score of 1 to a maximum score of 5 , arranged from strongly agree, agree, neutral, disagree, to strongly disagree.

In another section, open-ended questions were used to enable respondents to have maximum freedom to express their views in their own words. This was meant to offset any bias there might have been in closed-ended questions (Fasold, 1984:192).

The students' questionnaire was worded in both isiZulu and English throughout. In the same vein, students were permitted to respond in any or both languages. This was 
to ensure that the questions were understood as intended, and so to give credibility to the findings. However, the lecturers' questionnaire was in English only since they were believed to have an adequate command of the language they were employed to teach.

\section{Conducting the research}

The research tool was a self-administered paper-based questionnaire. Prior to administering it, the tool was piloted using a sample of 60 participants. The teaching and learning materials were developed over a period of three semesters and underwent a number of revisions.

Some of the student questionnaires were given to lecturers to administer in their respective classes. Others were personally administered by the researcher after negotiating time with the lecturers concerned. Lecturers' questionnaires were handed to them in person.

\section{Results and analysis}

The purpose of this section is to analyse the data obtained and to provide the results of the study. The approach is to focus on pertinent themes and issues and to compare the responses of lecturers with those of students. Hence, related questions are discussed together with the focus on study goals.

\section{Students' profile}

The majority of the 300 students surveyed (69\%) were in the age group 16 to 19 . This is consistent with the age group that would have been in Grade 12, the last year of schooling, in the previous year. Owing to financial and other social problems, not everyone is able to start higher education immediately after Grade 12. This explains the high number of students in the age groups 20 to $24(29 \%)$ and $25+(2 \%)$. The aim in requesting this information from participants was to assess whether age had any influence on language attitude. It would appear that this variable did not have a notable impact.

The student sample had a fairly equal gender distribution of 59\% male and $41 \%$ female. The slight male dominance could have resulted from the fact that engineering has historically been associated with males.

The majority of students (94.9\%) had isiZulu as their home language, while 3\% were isiXhosa speaking, 1\% Tshivenda speaking and 1\% siSwati speaking. Three respondents did not indicate their home language. The dominance of isiZulu-speaking students was expected and served to confirm the general dominance of isiZulu in the institution, the province and the country. The results are a true reflection of the student population of the institution.

It is because of the dominance of isiZulu as a primary language in the institution that teaching and learning materials were only in isiZulu. However, this was not favourably received by some of the respondents who felt that it was unfair to use isiZulu when there were speakers of other African languages in the programme. This feeling of 
discontent is consistent with findings by Dyers (cited in Dalvit \& De Klerk, 2005). It could be important to gradually add other languages in future depending on demand and the availability of resources. This would augur well for the recognition of all languages and the promotion of multilingualism in the institution and the country at large. Of the students, $86 \%$ indicated that they had completed their schooling in former black schools, whilst the remaining 14\% had been to multiracial schools.

\section{Lecturers' profile}

The majority of the lecturers ( 8 out of 10 ) were over the age of 40 . Of the remaining two lecturers, one was in the age group 30 to 35 and the other in the age group 36 to 40 . In this small sample there were more females (7) than males (3). The homelanguage profile indicates that the majority (6) of respondents were isiZulu speakers while there were three English first-language speakers and one seTswana speaker.

The dominance of ESL speakers among lecturers suggests that they were able to identify with the challenges often experienced by ESL learners, whereas their home language (isiZulu) would enable them to refer to the information in the material and then to explain it to the students in the students' home language. This would ensure that students understood the subject matter presented in English. However, in the case of lecturers not proficient in isiZulu this was not expected to be a problem as students would have noted the concepts and examples on their own to facilitate their understanding. The use of an African language in the teaching and learning material was meant to facilitate students' understanding rather than to compel lecturers to teach in both languages.

\section{Research goals}

As mentioned, the goal of the research was to examine the impact of a bilingual programme on biliteracy, bi- or multilingualism and language attitudes as reported by students and lecturers. The findings that follow are based on percentages of each response on a scale of $\mathrm{l}$ (strongly agree) to 5 (strongly disagree) for the selected questions. These are discussed with reference to the open-ended responses in an attempt to assess consistency in the responses. The responses from both the students and the lecturers are discussed together to enable a comparison. Each of the three research goals is named before the analysis of findings is explored.

\section{Biliteracy}

Biliteracy is viewed as literate competencies in two or more languages, to whatever degree, for communication purposes in education and society (Dworin, 2003; Hornberger, 2003). The first four questions asked the students to assess the effectiveness of the use of isiZulu in the guide. The results indicate that the majority (86\%) of students felt that they benefited from the mixing of an African language with English in the guide. They were also generally satisfied (87\%) with the quality of the content provided. The lecturers' assessment (80\%) regarding students' appreciation of the use of their primary language concurred with students' satisfaction with this approach (86\%). These findings are confirmed in the open-ended responses: 
It helped us to develop our understanding about our mother language and other languages and we also experienced more words which we were unfamiliar with them.

It improves the language of English and helped me to develop competence in the style of thinking required in my content subjects.

The students' positive responses are consistent with the study's hypothesis that students would relate to and benefit from this kind of bilingual programme. The guide provided them with a vehicle to do what they generally do during their learning: to draw from their first language in order to assimilate information presented in a second language. Moreover, during their schooling they would have been exposed to what is known as code-switching (CS), which is the alternate use of two or more languages in the same discourse, sentence, utterance or conversation (MyersScotton, 1993; Poplack, 2004). Moodley (2003) points out that according to research conducted in the school environment around Africa it has been demonstrated that CS is a communicative resource that allows educators and learners to accomplish many educational and social objectives. This suggests that the majority of African students who went through this type of supportive education find the transition to Englishonly medium of instruction at pre-university and first-year level quite sudden and traumatic. Failure to cope with the trauma leads to underachievement, low throughput rates and an alarming drop-out rate.

The students' views found support from the majority of lecturers (8) who believed that the use of students' primary language in the English class enhanced students' interest during lectures. However, when asked to indicate the effectiveness of the guide's approach in respect of their teaching, the lecturers appeared to be divided. While five agreed that the guide resulted in effective lecture delivery, two were not sure and three disagreed. It was however not surprising to discover that those who agreed as to the effectiveness of the guide in teaching were first-language speakers of isiZulu. This led to the assumption that the guide probably presented the approach they normally adopted in their classes to assist their students in that they would codeswitch from time to time.

The next set of questions was meant to enable participants to indicate the effects of the dual-language programme on English acquisition. The majority of students (96\%) felt that the guide enabled them to understand and use English better. They claimed that the guide developed their desire to continue learning English (84\%) and also enabled them to develop their English vocabulary (87\%). They were also consistent in their responses to open-ended questions:

I learnt to understand different meanings.

It helps most of the learners especially those who are struggling in English, who do not have the base on it.

Of the lecturers, seven agreed that the use of isiZulu contributed to English literacy. Their responses to the suggestion that the use of isiZulu retarded the development of students' English showed that the majority (7) disagreed. In keeping with this 
response, nine of the lecturers also disagreed that the use of isiZulu during the English lecture could have resulted in language confusion. Instead, lecturers evaluated the guide positively, even in their open-ended responses:

The translated explanations in isiZulu are useful.

The learning material is relevant to students' present and likely future needs - at university and in the workplace.

The next set of questions aimed to establish whether the use of isiZulu in the guide impacted on students' participation in class. The assumption was that most students would previously not have participated in an English class for fear that they might make embarrassing grammatical mistakes. With the use of a DLI guide, an overwhelming majority (73\%) indicated that they felt free to express themselves in a bilingual class.

The question on the use of language in the lecture room revealed that the majority of lecturers agreed that students tended to use more of their home language and less English. It was interesting to note that despite what lecturers might have viewed as negative (that students used their home language in the English class) nine of the lecturers believed that the use of isiZulu created a good rapport between them and their students. Moreover, as previously indicated, it contributed to the effective learning of English.

\section{Bi- or multilingualism}

The terms bilingualism and multilingualism are both understood to refer to situations, such as often found in South Africa, in which people use and are exposed to two or more languages in their everyday lives. The majority of students $(80 \%)$ felt that the use of their primary language in the teaching of English and literacy skills enabled them to think critically about the relationship between different languages. They equally showed this awareness about multilingualism when they expressed their reservations about the fact that only one African language was used, as indicated in their open-ended responses:

If you include Zulu only what about the guys who are not Zulus.

It used different languages. It helps people like me who need to use this guide more in future.

To speak and respect other languages.

At the same time, while most lecturers felt that the piloted DLI material broadened their perspective on bi- or multilingual education, they also had some reservations about the use of an African language during English classes. These sentiments were evident in their open-ended responses:

It is a move in the right direction to help students understand abstract terms and concepts to enable them to improve both their English and isiZulu competence and academic achievement. 
Not all students benefit from the use of isiZulu since it is not their first language. At the same time though, the role of isiZulu to teach English cannot be overlooked. It also helps the non-isiZulu-speakers to learn the basics of the language.

The positive views with regard to bi- or multilingualism are consistent with the finding made by Gómez, Freeman and Freeman (2005) in the United States. They indicate that DLI programmes have raised the status and importance of languages other than English. Students see great value in knowing more than one language. This bodes well for the preservation and maintenance of isiZulu in South Africa.

\section{Language attitudes}

The working definition of the concept 'attitude' adopted in the current study is that it is 'a feeling, reaction or emotional disposition towards an idea, concept or phenomenon' (Batibo, 2005:97). Along similar lines, this survey of language attitudes aimed to establish whether the respondents react positively or negatively to the phenomenon of bilingual education within which an African language is used alongside English in a higher education context. To this end, there were questions that were meant to establish how the bilingual programme had enabled the participants to begin to value the role of the home language in education.

The majority $(77 \%)$ of students felt that through the use of the DLI guide they learnt to value the role of their home language in education. In addition, $48 \%$ felt that the programme provided them with opportunities to develop their home language vocabulary. Upon scrutiny of respondents' school background, it was not surprising to note that $22 \%$ of the $48 \%$ had attended former model C schools where African languages could often be taken as a second or third language. The rest of the students $(52 \%)$ who felt that the programme did not develop their isiZulu vocabulary were assumed to be quite proficient in isiZulu because they had developed it both at school and at home. Open-ended responses were consistent with the closed-ended responses:

I have learnt a lot because what I did not understand in English was written in Zulu and vice versa.

It prepares me for future situation and even more on my career course.

To be able to communicate better in two languages.

The same sentiments were expressed in the lecturers' open-ended responses to the question of whether they would recommend this type of teaching material for other courses or content subjects. The majority of lecturers responded in the affirmative, while only three responded in the negative. This is a sample of their responses:

Yes. It will help both lecturers and students respect isiZulu as a language of academia.

No. I don't think that the return to the translation method of teaching language has benefits for mastering the target language. Of course the 
teacher, if s/he knows the learner's home language can use it for illustrative purposes, but to teach a language through another may not be beneficial.

Together, the responses from learners and lecturers were taken as support for the development of and a high regard for the role of African languages in education and society.

\section{Discussion and conclusions}

The findings of the study indicate participants' positive language attitudes, as well as support for the use of African languages in higher education. The positive attitudes are attributed to the fact that the respondents based their responses on their immediate experiences and perceived benefits of the use of isiZulu in the teaching and learning of academic literacy and communication skills.

It is worth noting that the bilingual programme was made possible by the fact that the setting of the project (MUT) has one predominant African language (isiZulu) in a country with nine official African languages that all need to be developed. In the spirit of multilingualism it would have been ideal to use more than one African language. However, due to constraints of time and resources this was not practical.

Since the study was undertaken during the teaching of the English language, it was important to determine how the subjects would perceive the use of isiZulu because of the controversy regarding straight-for-English and the use of a first language as a resource. Interestingly, both students and lecturers found value in the use of a first language to facilitate the teaching and learning of a second language.

The generally positive views regarding the use of an African language in higher education are pleasing. It is hoped that they will encourage colleagues in various departments and institutions of higher learning to begin to find ways to implement a multilingual policy in education as a possible mechanism to address current problems. Further studies could also assess participants' views in relation to their academic records and even beyond first-year level.

\section{Acknowledgements}

The information used in this chapter formed part of a $\mathrm{PhD}$ thesis in linguistics at the University of KwaZulu-Natal (Howard College) under the supervision of Professor Heike Tappe. The research was also undertaken as an institutional project at MUT registered with the Research Directorate and funded by the National Research Foundation from 2008 to 2009.

\section{References}

Batibo, H.M. 2005. Language decline and death in Africa: Causes, consequences and challenges. Clevedon: Multilingual Matters.

Cohen, L., Manion, L. \& Morrison, K. (eds). 2001. Research methods in education. London: Routledge. 
Cummins, J. 2005. Teaching and learning two languages in the EFL setting. Paper presented at the TESOL Symposium on Dual Language Education, Istanbul, Turkey.

Dalvit, L. \& De Klerk, V. 2005. Attitudes of Xhosa-speaking students at the University of Fort Hare towards the use of Xhosa as a language of learning and teaching (LOLT). Southern African Linguistics and Applied Language Studies, 23(1):1-18.

Dworin, J. 2003. Insights into biliteracy development: Toward a bidirectional theory of bilingual pedagogy. Journal of Hispanic Higher Education, 2:171-186.

Fasold, R. 1984. The sociolinguistic of society. Oxford: Blackwell.

Gómez, L., Freeman, D. \& Freeman, Y. 2005. Dual language education: A promising 50-50 model. Bilingual Research Journal, 29, Spring:1.

Heugh, K. 2005. Mother-tongue education is best. HSRC review, 3(3):6-7.

Helmberger, J.L. 2006. Language and ethnicity: Multiple literacies in context, language education in Guatemala. Bilingual Research Journal, 30(1):65-86.

Hornberger, N (ed.). 2003. Continua of biliteracy: An ecological framework for educational policy, research, and practice in multilingual settings. Clevedon: Multilingual Matters.

Lee, S.K. 2002. The significance of language and cultural education on secondary achievement: A survey of Chinese American and Korean American students. Bilingual Research Journal, 26(2):327-340.

Likert, R.A. 1932. A technique for the measurement of attitudes. New York: Columbia University Press.

Macfarlane, D. 2007. Dropouts - in their own words. Mail \& Guardian Online, 20 November [Online]. Available: www.mg.co.za [2007, 25 November].

Makhode, T. 2005. Ministerial spokesperson report on indigenous languages in higher education. Press release, 15 March.

Moodley, V. 2003. Language attitudes and code-switching behaviour of facilitators and learners in language, literacy and communication senior phase outcomes-based education classrooms. Unpublished PhD thesis, University of Natal, Durban.

Myers-Scotton, C. 1993. Social motivations for code-switching: Evidence from Africa. Oxford: Clevedon Press.

Ngcobo, S. 2001. IsiZulu-speaking educators' attitudes towards the role of isiZulu in education in Durban. Unpublished MA thesis, University of Natal, Durban.

Ngwenya, T. 2006. Integrating language awareness with critical language skills: A legal English experience. Southern African Linguistics and Applied Language Studies, 24(1):23-33.

Nunan, D. 1992. Research methods in language learning. Cape Town: Cambridge University Press.

Poplack, S. 2004. Code-switching. In: U. Ammon, N. Dittmar, K.J. Mattheier \& P. Trudgill (eds). Sociolinguistics. An international handbook of the science of language. 2nd ed. Berlin: Walter de Gruyter. 589-596.

RSA (Republic of South Africa). Department of Education. 2002. Language policy for higher education. Pretoria: Government Printer.

Ramani, E., Joseph, M. \& Modiba, M. 2007. Terminology vs. concept development through discourse: Insights from a dual-medium BA degree, in seSotho sa Leboa and English. Unpublished paper presented at LSSA/SAALA/SAALT Joint Annual Conference, North-West University, Potchefstroom, South Africa. 4-6 July.

Saville-Troike, M. 2003. The ethnography of communication: An introduction. 3rd ed. Oxford: Blackwell.

Shembe, S. 2003. IsiZulu as a teaching, learning and assessment tool in chemistry in higher education. PanSALB, January-March:6-8.

Statistics South Africa. 2003. Statistics and graphs: Percentage of speakers per language in South Africa. Pretoria: Government Printer.

Triandis, H. 1971. Attitude and attitude change. New York: Wiley. 
Van Dyk, T.J. 2005. Towards providing effective academic literacy intervention. Per Linguam, $21(2): 38-51$.

Webb, V.N. 2002. Language in South Africa. The role of language in national transformation, reconstruction and development. Amsterdam/New York: John Benjamins.

- 2004. Using the African languages as media of instruction in South Africa: Stating the case. Language Problems and Language Planning, 28(2):147-174.

Weideman, A.J. 2006. Assessing academic literacy: A task-based approach. Language Matters, 37(1):81-101.

Zeng, Z. \& Murphy, E. 2007. Tensions in the language learning experiences and beliefs of Chinese teachers of English as a foreign language. Teaching English as a Second or Foreign Language, 10(4): 1-19. 


\section{Appendix 1: Student questionnaire}

\section{SECTION A: OKUMAYELANA NAWE/PERSONAL DETAILS}

Isigaba sokuqala semibuzo sihlose ukuthola ulwazi mayelana nomfundi ophendula imibuzo yalolucwaningo. Khombisa ngophawu oluwumbaxa $(\mathrm{X})$.

The first set of questions is meant to gather some background information about a student who answers this questionnaire. Mark with a cross $(\mathrm{X})$ where possible.

1. Ubudala/Age

16-19 20-24 Over 25

2. Ubulili/Gender

Male female

3. Ulimi lwami/Home language

\begin{tabular}{|l|l|l|}
\hline IsiZulu & isiXhosa & Tshivenda \\
\hline SiSwati & seSotho & Other \\
\hline
\end{tabular}

4. Uhlanga lwabafundi esikoleni owagogoda kulo izifundo zikamatekeletsheni. The racial composition of students from your last high/secondary school.

\begin{tabular}{l|l} 
Multiracial & African \\
\hline esixubile & Abomdabu \\
\hline
\end{tabular}




\section{SECTION B: BILINGUAL LEARNER GUIDE EVALUATION}

Cross (X) ONE of the options at the end of each statement that represents your most honest response to the given statement. The letters stand for:

Phambanisa umdwebo (X) ekupheleni kwesitatimende ngasinye ukutshengisa umbono wakho weqiniso ngokuthi ukhethe uhlamvu olulodwa. Izinhlamvu zimele lokhu:

$\mathrm{A}=$ strongly agree/ngivuma ngokungananazi $; \mathrm{B}=$ Agree $/$ Ngiyavuma $; \mathrm{C}=$ Not sure/Angizazi;

$\mathrm{D}=$ Disagree/Angivumi $; \mathrm{E}=$ Strongly disagree/Angivumi sanhlobo

5. I found the mixing of languages in the guide suitable for my style of learning. Ukuxutshwa kwezilimi encwadini kuyazwana nendlela engifunda ngayo.

6. The guide enabled me to understand and use English better.

Incwadi yenze ngikwazi ukusiqonda kalula isiNgisi.

7. I experienced effective learning.

Ngifunde ngedlela egculisayo.

A B C D E

8. The guide helped me develop competence in the forms of reading,

writing and thinking required in my content subjects.

Ngikwazile ukuthuthukisa amakhono okufunda, ukubhala

nokucabanga okudingakalayo ezifundweni zami.

9. I felt free to express myself in class.

Ngizizwe ngikhululekile ukuphawula egunjini lokufunda.

10. I had opportunities to develop my English vocabulary.

Ngithole ithuba lokukhuphula ulwazi lwamagama esiNgisi.

A B C D E

11. I was able to think critically about the relationship between the different languages.

Ngikwazile ukucabanga kanzulu ngendlela izilimi

ezihlobene ngayo.

12. I learnt to value the role of my home language in education.

Ngifunde ukuhlonipha iqhaza elingabanjwa ulimi lwami

kwezemfundo.

13. I had opportunities to develop my isiZulu vocabulary.

Ngithole ithuba lokuthuthukisa ulwazi lwamagama esiZulu.

14. I would support the use of African languages in other subject guides.

Ngingaku xhassa ukusetshenziswa ko limu lwesintu nakwezinye izifundo. 


\section{SECTION C: DETAILED INFORMATION}

The next five questions require detailed answers. Feel free to explain in either isiZulu or English.

15. What do you think are the strengths of this subject's learner guide? Yini encomekayo ngencwadi yalesi sifundo?

16. What are the weaknesses of this subject's learner guide? Yini engeyinhle ngencwadi yalesi sifundo?

17. What suggestions do you have for improving this subject's guide? Iziphi izincomo ongazibeka ukuze isifundo sithi ukuthuthukiswa?

18. What are the most valuable things you have learnt through your participation in this type of subject that uses two languages?

Iziphi izinto ezibalulekile ongathi uzizuzile ngokuba yingxenye yalesi sifundo esixuba izilimi?

19. Any general comments?

Okunye ongathanda ukukubeka? 


\section{Appendix 2: Lecturer questionnaire}

\section{SECTION A: PERSONAL DETAILS}

Even though your participation in this study is anonymous, we would however appreciate it if you could provide the following general information about yourself:

1. Age group:

$$
\text { 30-35 }
$$

$36-40$

$41-45$

$46-50$

Over 50

2. Gender:

$$
\text { Male Female }
$$

3. First/home language:

\section{SECTION B: LEARNER GUIDE EVALUATION}

Please ring the response that you think is most appropriate to each statement. If you wish to make any comments in addition to these ratings please do so on the back page.

\section{The use of isiZulu in the guide:}

4. Encourages students to participate in classes.

5. Helps students develop literacy in English.

6. Is appreciated by students.

7. Develops students' interest during lectures.

8. Results in effective lecture delivery.

9. Retards the development of students English proficiency.

10. Results in language confusion.

11. Enables students to freely use their home language in class.

12. Enables students to freely use English in class.

13. Creates a good rapport with learners.

14. Broadens my perspective on bilingual/multilingual education.

\section{Strongly \\ Agree}
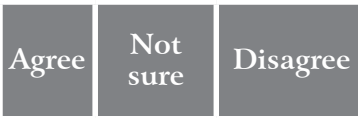

Strongly

Disagree

5
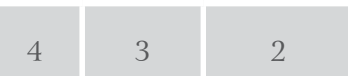

1

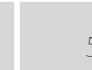

5

4

3

2

1

5

5

5

4

3

2

I

4

3

2

4

2

1

5

4

3

2

5

4

3

5

4

5

4

\section{3}

\begin{tabular}{|l|}
\hline 2 \\
\hline 2
\end{tabular}

1

\begin{tabular}{|l|l|l|}
\hline 3 & 2 & 1 \\
\hline 3 & 2 & 1 \\
\hline 3 & 2 & 1 \\
\hline
\end{tabular}




\section{SECTION C: DETAILED INFORMATION}

The following five questions require slightly more detailed answers. Use the back of the page if necessary.

15. What are the best features of the guide?

16. What are the worst features of the guide?

17. Where can improvement be made in the guide?

18. Would you recommend the style of this guide to other content subjects and English lecturers/educators? Briefly explain.

19. Are there any other comments you wish to make about the use of isiZulu to teach English? 